\title{
Ion mass spectrometry investigations of the discharge during reactive high power pulsed and direct current magnetron sputtering of carbon in Ar and Ar/N-2
}

Susann Schmidt, Zs Czigany, Grzegorz Greczynski, Jens Jensen and Lars Hultman

\author{
Linköping University Post Print
}

N.B.: When citing this work, cite the original article.

Original Publication:

Susann Schmidt, Zs Czigany, Grzegorz Greczynski, Jens Jensen and Lars Hultman, Ion mass spectrometry investigations of the discharge during reactive high power pulsed and direct current magnetron sputtering of carbon in Ar and Ar/N-2, 2012, Journal of Applied Physics, (112), 1, 013305.

http://dx.doi.org/10.1063/1.4733692

Copyright: American Institute of Physics (AIP)

http://www.aip.org/

Postprint available at: Linköping University Electronic Press

http://urn.kb.se/resolve?urn=urn:nbn:se:liu:diva-80790 


\title{
lon mass spectrometry investigations of the discharge during reactive high power pulsed and direct current magnetron sputtering of carbon in $\mathrm{Ar}$ and $\mathrm{Ar} / \mathrm{N}_{2}$
}

\author{
S. Schmidt, ${ }^{1, a)}$ Zs. Czigány, ${ }^{2}$ G. Greczynski, ${ }^{1}$ J. Jensen, ${ }^{1}$ and L. Hultman ${ }^{1}$ \\ ${ }^{1}$ Thin Film Physics Div., Department of Physics (IFM), Linköping University, SE-581 83, Sweden \\ ${ }^{2}$ Institute of Technical Physics and Materials Science, Research Centre for Natural Sciences, \\ Hungarian Academy of Sciences, Konkoly Thege Miklós út 29-33. H-1121 Budapest, Hungary
}

(Received 18 February 2012; accepted 2 June 2012; published online 9 July 2012)

\begin{abstract}
Ion mass spectrometry was used to investigate discharges formed during high power impulse magnetron sputtering (HiPIMS) and direct current magnetron sputtering (DCMS) of a graphite target in $\mathrm{Ar}$ and $\mathrm{Ar} / \mathrm{N}_{2}$ ambient. Ion energy distribution functions (IEDFs) were recorded in time-averaged and time-resolved mode for $\mathrm{Ar}^{+}, \mathrm{C}^{+}, \mathrm{N}_{2}{ }^{+}, \mathrm{N}^{+}$, and $\mathrm{C}_{\mathrm{x}} \mathrm{N}_{\mathrm{y}}{ }^{+}$ions. An increase of $\mathrm{N}_{2}$ in the sputter gas (keeping the deposition pressure, pulse width, pulse frequency, and pulse energy constant) results for the HiPIMS discharge in a significant increase in $\mathrm{C}^{+}, \mathrm{N}^{+}$, and $\mathrm{CN}^{+}$ion energies. $\mathrm{Ar}^{+}, \mathrm{N}_{2}{ }^{+}$, and $\mathrm{C}_{2} \mathrm{~N}^{+}$ion energies, in turn, did not considerably vary with the changes in working gas composition. The HiPIMS process showed higher ion energies and fluxes, particularly for $\mathrm{C}^{+}$ions, compared to DCMS. The time evolution of the plasma species was analyzed for HiPIMS and revealed the sequential arrival of working gas ions, ions ejected from the target, and later during the pulse-on time molecular ions, in particular $\mathrm{CN}^{+}$and $\mathrm{C}_{2} \mathrm{~N}^{+}$. The formation of fullerene-like structured $\mathrm{CN}_{\mathrm{x}}$ thin films for both modes of magnetron sputtering is explained by ion mass-spectrometry results and demonstrated by transmission electron microscopy as well as diffraction. (C) 2012 American Institute of Physics. [http://dx.doi.org/10.1063/1.4733692]
\end{abstract}

\section{INTRODUCTION}

Carbon based thin films comprise all three valence hybridization states $\left(s p^{3}, s p^{2}, s p\right)$ yielding manifold bonding configurations and microstructures, including amorphous (a-C), graphitic, polymer-like, and diamond-like carbon (DLC). ${ }^{1,2}$ Consequently, the properties of such compounds can be modified over a wide range justifying the intense research and development of this technologically important material. ${ }^{1,3-7}$ In the past, carbon films have been prepared by numerous deposition techniques among them are PECVD (plasma enhanced chemical vapor deposition), ${ }^{8}$ DCMS (direct current magnetron sputtering), ${ }^{9}$ r.f.-MS (radio frequency magnetron sputtering), ${ }^{10}$ laser ablation, ${ }^{3,4}$ as well as filtered cathodic arc deposition. ${ }^{8,11}$ DLC coatings, in particular, were reported to exhibit a superior wear resistance, hardness, chemical inertness ${ }^{1,5,12,13}$ and biocompatibility, ${ }^{14}$ as well as electrical insulation and infrared transparency. ${ }^{15}$ Consequently, carbon coatings found their way into industry, for example, as wear resistant protective layers ${ }^{16}$ and optical coatings for infrared and visible ranges. ${ }^{15}$ Their properties might also have potential in very large scale integration (VLSI), medical implants, ${ }^{14}$ and applications in green technology.

Carbon films may be further functionalized by introducing another element into the $\mathrm{C}$ matrix. Nitrogen, for example, is likewise able to adopt numerous bonding structures. Thus, carbon-nitride $\left(\mathrm{CN}_{\mathrm{x}}\right)$ compounds exhibit several

\footnotetext{
${ }^{\text {a) }}$ Author to whom correspondence should be addressed. Electronic mail: sussc@ifm.liu.se. Tel.: +46 13288 974. Fax: +46 13137568.
}

allotropes, depending on how the carbon network is arranged. Among them graphite-like, fullerene-like (FL), and DLC-like compounds can be found. ${ }^{17-19}$ This implies further changes with regards to the film properties such as hardness, density, and film stress. ${ }^{18-22}$ For amorphous and FL-CN ${ }_{\mathrm{x}}$ films grown by DCMS moderate-to-high hardness values, ranging between $6 \mathrm{GPa}$ and $15 \mathrm{GPa}$ were reported. ${ }^{17,19,23}$ Moreover, a superior resiliency (elastic recovery of up to $98 \%$ ) as well as a reduced wear and friction, similar to those of DLC films, were shown. ${ }^{19,24}$ Thus, FL-CN ${ }_{\mathrm{x}}$ thin films were described with the term "super hard rubber." ${ }^{24}$ Naturally, such properties make $\mathrm{CN}_{\mathrm{x}}$ thin films attractive for tribological coatings. Important DCMS growth parameters for the modification of the $\mathrm{CN}_{\mathrm{x}}$ thin film microstructure and consequently properties are the substrate temperature $\left(\mathrm{T}_{\mathrm{s}}\right)$, the degree of ion-bombardment, and the nitrogen-to-argon flow ratio $f_{N 2 / A r}{ }^{24}$

Novel ionized deposition techniques such as HiPIMS (high power impulse magnetron sputtering) widen the process window to produce carbon-based wear resistant thin films with even further tailored functional properties. From a historical perspective, HiPIMS was developed from DCMS and first described in 1999 by Kouznetsov et al. ${ }^{25}$ Due to the operation of the sputtered target with short, but high power pulses, ultra dense, and highly ionized plasmas were reported for commonly sputtered metals. ${ }^{26,27}$ The increased ionization is a consequence of the significantly reduced mean free path for collisions with plasma electrons (electron impact ionization), of approximately $10 \mathrm{~mm}$ in contrast to $500 \mathrm{~mm}$ for DCMS. ${ }^{25,27,28}$ The higher amount of ionized sputtered material was reported to create denser films attributed to an 
increased surface mobility of the adatoms arriving at the substrate. ${ }^{29-31}$ Furthermore, HiPIMS films were found to exhibit in many cases a changed morphology compared to films sputtered under comparable DCMS or cathodic arc conditions. However, only few reports deal with HiPIMS employing a graphite target. DeKoven et al. reported ionized flux fraction to be as low as $4.5 \%$ for graphite. ${ }^{32}$ Hecimovic et al. presented first ion energy distribution functions (IEDFs) measured for $\mathrm{C}$ sputtered in Ar atmosphere in context with data obtained from $\mathrm{Cr}$ and $\mathrm{Ti}^{33}$ They found increased metal ion-to-gas ion ratios with an increased sputter yield of the target material. Additionally, the origin of IEDFs was investigated and two contributions were established; the first arising due to low energetic ions originating from ions of the post discharge, whereas the second is a broad high-energy tale, which increased with increasing target current. Recently, Hecimovic et al. ${ }^{34}$ published a comparative study on the temporal evolution of ion fluxes obtained from several elemental targets, including $\mathrm{C}$, during the HiPIMS discharge in argon. They suggested that the ion energy and the ion life span depend on collisions with plasma particles, for all considered elements. The life span was found to be longest for heavy mass elements due to rarefaction. Authors concluded that the energy losses are highest for masses similar to Ar. Furthermore, the metal ion energy was found to correlate with its binding energy in the solid. However, to our best knowledge, no reports have been published as for the investigation on the reactive graphite HiPIMS process in $\mathrm{Ar} / \mathrm{N}_{2}$ atmosphere. The characterization of the plasma becomes vital not only for an improved understanding of the synthesis process of $\mathrm{CN}_{\mathrm{x}}$ compounds but also in order to comprehend film properties.

Here, we report on mass-spectrometry measurements carried out with a graphite target, sputtered either in HiPIMS or in DCMS mode in $\mathrm{Ar}$ and $\mathrm{Ar} / \mathrm{N}_{2}$ atmosphere. Timeaveraged IEDFs obtained during HiPIMS are compared to those acquired for the DCMS processes. In addition timeresolved HiPIMS, data are collected and analyzed in detail. Conclusions on the $\mathrm{CN}_{\mathrm{x}}$ growth mechanisms and the $\mathrm{C}$ and $\mathrm{CN}_{\mathrm{x}}$ film microstructure are drawn from mass-spectrometry results in combination with the evaluation of target current and target voltage waveforms as well as transmission electron microscopy (TEM) images and selected area electron diffraction (SAED) patterns.

\section{EXPERIMENTAL DETAILS}

All ion mass-spectrometry measurements and film depositions were performed in the industrial coating system CC800/9 (CemeCon AG, Germany). Here, two out of four cathodes can be driven in HiPIMS mode; furthermore, the system offers the possibility to operate those two HiPIMS cathodes, as well as, the substrate table simultaneously in HiPIMS mode. Plasma characterization and film depositions were carried out in both modes-HiPIMS and DCMS. For our investigations, one rectangular target with an area of $440 \mathrm{~cm}^{2}$ was sputtered in an $\mathrm{Ar}$ or $\mathrm{Ar} / \mathrm{N}_{2}$ atmosphere at a constant pressure of $400 \mathrm{mPa}$ in the power-regulated mode. In the case of HiPIMS, the cathode was driven with frequencies of $300 \mathrm{~Hz}$ and $500 \mathrm{~Hz}$, the average power ranged between $700 \mathrm{~W}$ and $2000 \mathrm{~W}$, and the pulse width was kept constant in all processes at $200 \mu \mathrm{s}$. DCMS was carried out at a power of $2000 \mathrm{~W}$.

The IEDFs were measured in a time-averaged and timeresolved mode for $\mathrm{C}^{+}, \mathrm{Ar}^{+}, \mathrm{N}^{+}, \mathrm{N}_{2}{ }^{+}, \mathrm{CN}^{+}$, and $\mathrm{C}_{2} \mathrm{~N}^{+}$ions with a PSM003 unit from Hiden Analytical, UK. This mass spectrometer is equipped with a quadrupole mass analyzer and allows the measurement of masses up to $300 \mathrm{amu}$ with a resolution of $0.1 \mathrm{amu}$. Further details regarding the mass spectrometer are given in Ref. 35. In order to a allow comparisons, all measurements were carried out with the same global settings. During mass-spectrometry measurements, the cathode faced the spectrometer orifice at a distance of $210 \mathrm{~mm}$. Time-averaged data were measured in the range of $0.4 \mathrm{eV}-100 \mathrm{eV}$ applying step widths of $0.2 \mathrm{eV}$. Furthermore, the dwell time was set to $300 \mathrm{~ms}$, corresponding to an information depth of at least 90 pulses at each data point. In order to acquire time-resolved data, the mass-spectrometry measurements were triggered by a signal from a Tektronix DPO4054 $500 \mathrm{MHz}$ bandwidth digital oscilloscope. The delay time ranged from $40 \mu$ s up to $300 \mu$ s with an increment time of $20 \mu$ s and was related to the onset of the power pulse to the cathode. A total acquisition time of $1 \mathrm{~ms}$ per data point was applied. Ion energies were scanned in a range between $0 \mathrm{eV}$ and $30 \mathrm{eV}$ with a resolution of $0.5 \mathrm{eV}$. All time-resolved data presented were corrected for the ion time-of-flight (TOF) within the mass spectrometer. The approach given in Ref. 35 was used to show the plasma composition at the spectrometer orifice rather than at the detector. The TOF of the ions depends on their initial kinetic energy, but due to the fact that within an energy range between $0 \mathrm{eV}$ and $100 \mathrm{eV}$, the TOF differs not more than $10 \%$, a value of $8 \mathrm{eV}$ was used for all calculations. Target current and target voltage waveforms were recorded simultaneously.

Thin film depositions were carried out using the same, above mentioned power settings at the cathode. The substrates faced the rectangular, pure graphite target at a distance of $60 \mathrm{~mm}$. In the case the films were deposited by HiPIMS, a pulsed bias voltage $\left(\mathrm{V}_{\mathrm{b}}\right)$ of $-100 \mathrm{~V}$ was applied, whereas a DC bias voltage of $-100 \mathrm{~V}$ was applied during depositions in DCMS mode. Depositions were carried out at room temperature $(\mathrm{RT})$, at $\mathrm{T}_{\mathrm{s}}=110^{\circ} \mathrm{C}$ (LT-low temperature) and at $\mathrm{T}_{\mathrm{s}}=430^{\circ} \mathrm{C}(\mathrm{HT}$-high temperature $)$.

Using cross-sectional scanning electron microcopy (SEM, LEO 1550 Gemini, Zeiss, Germany), the deposition rates were determined. Composition and areal atomic density (atoms $/ \mathrm{cm}^{2}$ ) of the $\mathrm{CN}_{\mathrm{x}}$ films were evaluated using time-offlight elastic recoil detection analysis (ToF-ERDA) applying an $36 \mathrm{MeV}{ }^{127} \mathrm{I}^{9+}$ ion beam at $22.5^{\circ}$ incidence angle relative to the surface. ${ }^{36,37}$ Data were stored event by event in list mode and analyzed off-line. Only the data obtained during the first minutes (yielding sufficient statistics) were used.

For plan-view TEM, $\mathrm{CN}_{\mathrm{x}}$ films of less than $50 \mathrm{~nm}$ in thickness were deposited on cleaved $\mathrm{NaCl}$ substrates. These films were floated off in water, rinsed twice, and collected on a TEM Cu grid. Cross-sectional TEM was carried out on cleaved samples. ${ }^{38}$ Plan-view and cross-sectional samples were examined in a Tecnai G2 TF 20 UT TEM (FEI, 
The Netherlands). SAED patterns were exposed with a CCD camera in the same instrument. The diffraction patterns were processed with process diffraction software. ${ }^{39}$ The degree of structuring (fullerene-like, graphitic or plain amorphous) was assessed in evaluating peak intensities (int) of the ring $\sim 3.5 \AA$ and the $\sim 2 \AA$ ring, extracted from the SAED pattern. Setting both intensities into relation (int $(3.5 \AA) / \operatorname{int}(2 \AA)$ ) depicts the degree of structure; the higher the value, the higher is the degree of graphitic short range ordering. ${ }^{40}$

\section{RESULTS AND DISCUSSION}

\section{A. Target current and target voltage waveforms}

The energy per pulse $\left(\mathrm{E}_{\mathrm{p}}\right)$, as a commonly used process parameter in order to compare different processes settings, can be extracted by integrating the product of target current and target voltage over the pulse duration $\mathrm{d}_{\mathrm{p}}$. In Figure 1, target current and target voltage waveforms for different $\mathrm{E}_{\mathrm{p}}$ are illustrated for a pure graphite target, sputtered in Ar atmosphere. Evident is that the voltage is not constant throughout the entire pulse but decreases as soon as the charge is withdrawn from the capacitors. The target current scales according to: $\mathrm{I}(\mathrm{t})=\mathrm{C} d \mathrm{U}(\mathrm{t}) / d \mathrm{t}$, where $\mathrm{I}(\mathrm{t})$ and $\mathrm{U}(\mathrm{t})$ are assigned to the target current and target voltage, respectively, in dependency of time, and $\mathrm{C}$ is the capacitance. A comparison of target current and target voltage waveforms for commonly sputtered metals such as $\mathrm{Ti}, \mathrm{Cu}$, or $\mathrm{Cr}$ (see e.g., Ref. 41) to corresponding data plots for $\mathrm{C}$ shows clearly that the maximal applicable pulse energy is reduced in the later case. This implies a decreased total number of sputtered ions, owing to the comparatively high ionization potential of carbon $(11.26 \mathrm{eV})$ and the low sputter yield of 0.197 atoms/ion (in $\mathrm{Ar}$ with $500 \mathrm{eV}$ ) in the $\mathrm{C} / \mathrm{Ar}$ discharge. For the present sputter system and process settings, stable processes are

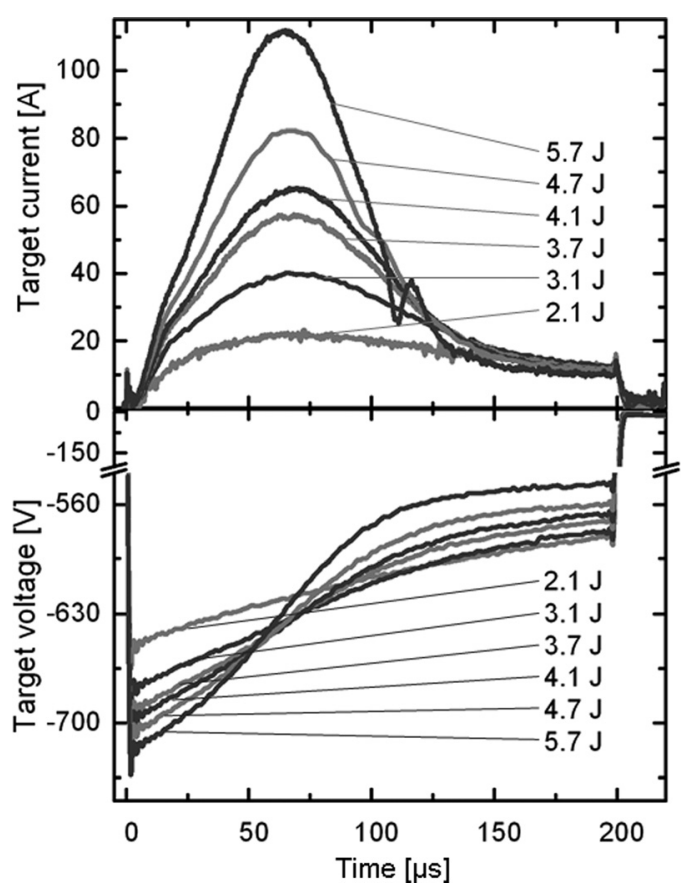

FIG. 1. Target current and target voltage waveforms for HiPIMS with different pulse energies and a pulse duration of $200 \mu \mathrm{s}$ in a C/Ar discharge. obtained for pulse energies lower than $6.0 \mathrm{~J}$ for the $\mathrm{C} / \mathrm{Ar}$ discharge.

Typical HiPIMS conditions on industrial-size targets are characterized by dynamic changes in the target current waveforms as can be seen in Figure 1 during the first $130 \mu$ s of the pulse. The rather stable current values, which can be observed in the last $70 \mu$ s of the pulses, reflect DCMS conditions. As can be seen in Figure 1, the drop of the voltage and thus the rise in current is not as pronounced in the C/Ar discharge compared to, e.g., the $\mathrm{Cr} / \mathrm{Ar}$ discharge described by Greczynski and Hultman, ${ }^{41}$ where pulse energies of up to $25 \mathrm{~J}$ were employed. The target current waveforms show instead a smooth transition from HiPIMS to DCMS discharge regimes. Interestingly, the $\mathrm{C}$ discharge for $\mathrm{E}_{\mathrm{P}}<3 \mathrm{~J}$ does not exhibit this distinct transition from the dynamic HiPIMS character to the steady DCMS regime, implying that a pulsed process under DCMS conditions takes place. As the pulse energy rises above $3.5 \mathrm{~J}$, the transition from HiPIMS to DCMS becomes more apparent with a dynamic region $(0 \mu \mathrm{s}-130 \mu \mathrm{s})$ and a less dynamic region $(130 \mu \mathrm{s}-$ $200 \mu \mathrm{s}$ ), where the target current decreases to a mean value of $11.5 \mathrm{~A}$. The transition from HiPIMS to DCMS regimes, seen for $\mathrm{E}_{\mathrm{P}}>3.5 \mathrm{~J}$, can potentially be ascribed to a combination of the effects of gas rarefaction and the decay of the cathode voltage. ${ }^{42}$ However, the effect of gas rarefaction (the depletion of sputter gas in the vicinity of the target) ${ }^{43}$ should be less pronounced in this case as the target current is comparatively low, hence, the sputtered flux is limited as well. Therefore, an effect of gas heating is not as prominent for the $\mathrm{C}$ discharge.

Figure 2 shows target current and target voltage waveforms recorded during the carbon discharge as a function of

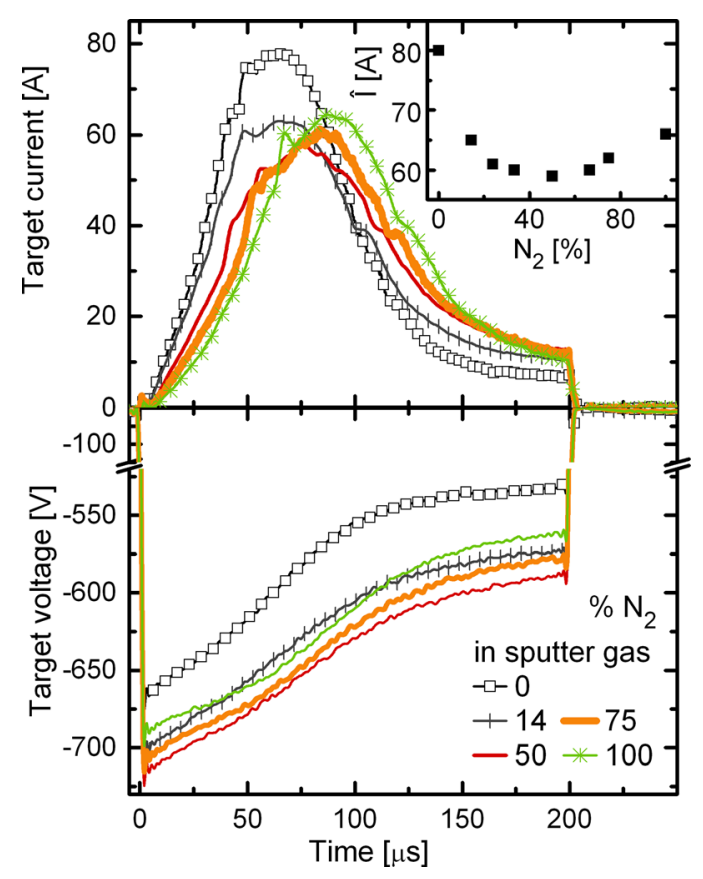

FIG. 2. Target current and target voltage waveforms in dependence of the $\mathrm{N}_{2}$ content in the sputter gas for selected HiPIMS processes (for reasons of clarity, data relating to five different $\mathrm{N}_{2}$ contents are shown). The inset illustrates the peak target current $(\hat{\mathrm{I}})$ with increasing $\mathrm{N}_{2}$ content in the sputter gas for the full experimental range. 
$\mathrm{N}_{2}$ in the sputter gas. Here, processes were carried out at constant process pressures of $400 \mathrm{mPa}$ and in all cases a similar $\mathrm{E}_{\mathrm{p}}$ of $4 \mathrm{~J}$ was applied. The above described characteristics are present throughout the whole range of introduced reactive gas contents. Apparent features related to the presence of $\mathrm{N}_{2}$ in the plasma are the considerable changes in the peak target current, and the current peak shift towards the end of the pulse. This suggests complex interactions in the plasma and/or at the target surface, compared to the case when $\mathrm{C}$ is sputtered in pure Ar. As can be seen in the inset of Figure 2, the peak target current has a minimum between $20 \%$ and $70 \%$ of $\mathrm{N}_{2}$ in the sputter gas. Upon exceeding $70 \%$ of reactive gas in the process, the target current rises again. As $\mathrm{C}$ is sputtered in pure $\mathrm{N}_{2}$ atmosphere, it reaches only $82 \%$ compared to the process in pure Ar. The observation of a decreased target current is characteristic for a suppressed amount of charged, sputtered species that form in the vicinity of the target and at the surface of the target whenever a reactive gas is involved in the sputter process. Thus, the effects resulting from changes in the secondary electron emission yield $\left(\gamma_{S E}\right)$ should be considered in this respect. ${ }^{44}$

The changed $\gamma_{S E}$ is a consequence from an altered sputter gas composition and the reactions taking place at the surface of the target. For the approximation of $\gamma_{S E}$, Eq. (1) ${ }^{42}$ is used.

$$
\gamma_{S E}=0.032\left(0.78 I_{P}-2 \phi\right),
$$

As can be drawn from Eq. (1), $\gamma_{S E}$ merely depends on $\mathrm{I}_{\mathrm{P}}$, the ionization potential of the impinging particles (sputter gas) on the target surface and $\phi$, the work function of the target material. It pertains to the argument that the ionization potentials for the most abundant species observed in the plasma such as nitrogen $\left(\mathrm{I}_{\mathrm{PN}}=14.5 \mathrm{eV}\right.$ (Ref. 45)), molecular nitrogen $\left(\mathrm{I}_{\mathrm{PN} 2}=15.6 \mathrm{eV}\right.$ (Ref. 45)), $\mathrm{CN} \quad\left(\mathrm{I}_{\mathrm{PCN}}=14.5 \mathrm{eV}\right.$ (Ref. 46)), and $\mathrm{C}_{2} \mathrm{~N}\left(\mathrm{I}_{\mathrm{PC} 2 \mathrm{~N}}=12.8 \mathrm{eV}\right.$ (Ref. 46)) are lower compared to that of $\mathrm{Ar}\left(\mathrm{I}_{\mathrm{PAr}}=15.8 \mathrm{eV}\right.$ (Ref. 47)). The approximation of the difference in $\gamma_{\mathrm{SE}}$ when the sputter process is carried out in pure Ar and pure $\mathrm{N}_{2}$, results in a lower secondary electron yield of $6 \%$ for the discharge in pure $\mathrm{N}_{2}$. Here, the same $\phi$ was used in both cases (sputtering in $\mathrm{Ar}$ or $\mathrm{N}_{2}$ ), since the exact $\phi$ of a modified target surface by nitrogen is unknown. The slight decrease of $6 \%$ obtained for $\gamma_{S E}$ cannot account for a lower target current of $17 \%$. Thus, the primary reason for this discrepancy seems to be the assumed constant work function of the target surface, when the sputter process is carried out in pure nitrogen. Naturally, the work function of the target surface depends on its chemistry and is altered during reactive sputtering.

In adopting the theory of a changed target surface chemistry with regards to the applied HiPIMS processes, it becomes conceivable that the pulse-off duration is sufficiently long for a reaction of the yet again "virgin" target surface (after the power pulse). Meaning, just after the power pulse, the target surface exhibits a low amount of C-N bonds, but sufficient $\mathrm{C}$ dangling bonds. Consequently, a recreation of the $\mathrm{C}_{\mathrm{x}} \mathrm{N}_{\mathrm{y}}$ target surface chemistry can take place due to impinging $\mathrm{N}_{\mathrm{x}}$ gas ions. Therefore, it is concluded that the changes in the discharge current seen for gradually increasing nitrogen contents are due to the changed target surface chemistry and to a smaller extent the changes in sputter gas chemistry. Previous studies on $\mathrm{C}$ sputtered in $\mathrm{Ar} / \mathrm{N}_{2}$ ambient by DCMS reported the physical sputter process to be significantly influenced by chemical sputtering provided the process took place with particle energies below $100 \mathrm{eV}$. Roth describes the general process of chemical sputtering in Ref. 48, developing a detailed kinetic model for atomic hydrogen with pyrolytic graphite. Jacob et al. ${ }^{49}$ and Schlüter et al. ${ }^{50}$ extended this model to interactions of atomic nitrogen with a graphite surface. According to them, chemical sputtering can be pictured as a multi-step process leading to the formation of volatile species such as $\mathrm{CN}, \mathrm{CHN}$, and $\mathrm{C}_{2} \mathrm{~N}_{2}$. The sequence for chemical sputtering can be illustrated with the following events. ${ }^{50}$

(i) Incident ions break the $\mathrm{C}-\mathrm{C}$ bonds within the range of their penetration depth causing dangling bonds. The penetration depth was modeled for $\mathrm{Ar}(20 \mathrm{eV})$ in graphite by transport of ions in matter (TRIM) to a maximum value of $13 \AA$.

(ii) The passivation of the dangling bonds by atomic nitrogen that arrives before a recombination of the $\mathrm{C}$ dangling bonds takes place with other elements such as $\mathrm{H}$ and $\mathrm{C}$.

(iii) In consequence of the repetition of (i) and (ii), volatile $\mathrm{CN}$-species form and desorb.

In summary, the chemical sputter mechanism is based on the dynamic adsorption and desorption of $\mathrm{C}_{\mathrm{x}} \mathrm{N}_{\mathrm{y}} / \mathrm{N}_{\mathrm{x}}$ plasma species. For lowered $\mathrm{N}_{2}$ contents in the sputter gas, impinging Ar might retard this mechanism by destroying $\mathrm{C}-\mathrm{N}$ bonds at the target surface. Therefore, it can be assumed that a chemical sputter process, to some extent, takes place at the target surface.

Another apparent feature seen in Figure 2 is the shift for the onset target current to rise and thus the peak target current shifts. Both are observed later in the pulse as the nitrogen content is increasing. This behavior can also be attributed to the events of chemical sputtering at the target.

\section{B. The HiPIMS carbon discharge as a function of the $\mathrm{N}_{2}$ content in the sputter gas: Time-averaged mass spectrometry and comparison to the DCMS discharge}

Generally, IEDFs recorded for a HiPIMS process contain two main components, which are (i) a low-energy peak, representing those ions, which lost their initial kinetic energy due to collisions (thermalization) and (ii) a high-energy tail. The latter reflects mainly three components: the probability function of electron impact ionization, the probability function for collisions to occur between metal ions and inert gas neutrals, and the energy transmission function of the mass spectrometer.

A qualitative comparison and closer examination of IEDFs, acquired during HiPIMS carbon discharges for different $\mathrm{N}_{2}$ contents in the sputter gas at a total constant process pressure of $400 \mathrm{mPa}$ is given in this section. Figures 3(a)-3(f) show IEDFs recorded at $E_{p}$ of $4 \mathrm{~J}$ and $500 \mathrm{~Hz}$ of the most abundant species arriving at the substrate. 


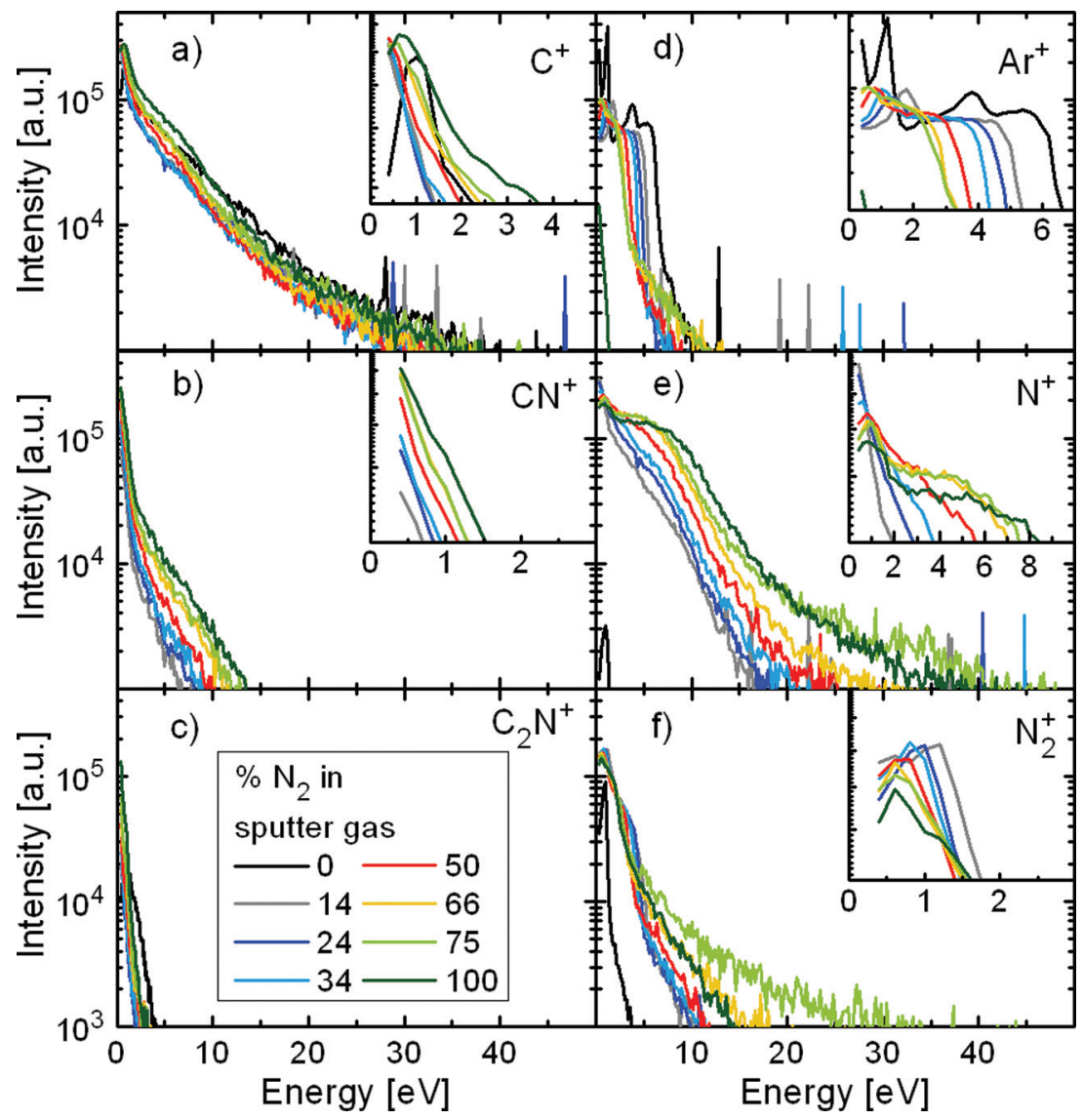

FIG. 3. (a)-(f) Time-averaged IEDFs of (a) $\mathrm{C}^{+}$, (b) $\mathrm{CN}^{+}$, (c) $\mathrm{C}_{2} \mathrm{~N}^{+}$, (d) $\mathrm{Ar}^{+}$, (e) $\mathrm{N}^{+}$, and (f) $\mathrm{N}_{2}^{+}$detected during mass spectrometry for the HiPIMS discharge of graphite in $\mathrm{Ar}$ and $\mathrm{Ar} / \mathrm{N}_{2}$ atmosphere. The insets show a magnification of the low-energy region.

The low-energy $\mathrm{C}^{+}$peak (cf. inset Figure 3(a)), originating from fully thermalized ions, shows a minimum energy around $50 \%$ of nitrogen in the sputter gas, which in turn, indicates a decreased plasma potential ${ }^{33}$ in this region. In detail, the energy of the low-energy $\mathrm{C}^{+}$peak observed at $\sim 1 \mathrm{eV}$ for a pure Ar discharge, decreases for processes with $\sim 50 \%$ of nitrogen in the plasma, and increases again to a value of $\sim 0.7 \mathrm{eV}$ as the discharge is carried out in pure nitrogen. The position of this low-energy peak mirrors the plasma potential, as the orifice of the mass spectrometer was grounded. However, since the signal of the low-energy $\mathrm{C}^{+}$ peak was recorded in time-average mode, it is dominated by contributions acquired during pulse off times due to low duty cycles. In other words, the extracted plasma potential is the time-averaged value over the whole period. Moreover, as can be observed in Figures 3(a) and 3(e), the IEDFs of $\mathrm{C}^{+}$and $\mathrm{N}^{+}$ ions are characterized by pronounced high-energy tails. IEDFs of $\mathrm{CN}^{+}, \mathrm{C}_{2} \mathrm{~N}^{+}, \mathrm{N}_{2}^{+}$, and $\mathrm{Ar}^{+}$do not exhibit such distinct high-energy tails, which is partly due to their higher masses, as well as larger sizes. Another factor for the qualitative difference in IEDF-shape might be that both the $\mathrm{C}^{+}$ions and the high energy $\mathrm{N}^{+}$ions are created by electron impact ionization and originate from the target as nitrogen reacts with the target material. In this respect, it may as well be possible that backattracted $\mathrm{N}_{2}{ }^{+}$dissociates at the target surface.

IEDFs of $\mathrm{CN}^{+}$move towards higher energies with increasing nitrogen content in the sputter gas, whereas the nitrogen content does not seem to influence the appearance of the $\mathrm{C}_{2} \mathrm{~N}^{+}$IEDFs. For both dimer groups, the comparatively high amount of fully thermalized (low energy) ions is apparent. This can be ascribed to the higher collision probability of those molecules due to their increased dimensions.

The IEDFs of the working gas ions recorded during HiPIMS are shown in Figures 3(d)-3(f). Remarkable features can be seen for Ar IEDFs. Here, the time-averaged measurement for carbon sputtered in pure argon atmosphere (black line) shows substantial amounts of fully thermalized and very low energy ions splitting at $\sim 0.4 \mathrm{eV}$ and $\sim 1.4 \mathrm{eV}$, respectively. This split of the low energy ions will be further discussed in Sec. III C where time-resolved measurements are taken into account. The low energy $\mathrm{Ar}^{+}$-peak moves from $\sim 0.4 \mathrm{eV}$, for a discharge in pure argon, towards a maximum energy of $\sim 1.8 \mathrm{eV}$ as soon as nitrogen is introduced into the sputter chamber $\left(\mathrm{N}_{2} \sim 14 \%\right)$, but drops again to an energy of $\sim 0.6 \mathrm{eV}$ as the nitrogen content rises further. This behavior is inconsistent with regards to the target current and target voltage waveforms and above described $\mathrm{C}^{+}$-IEDFs, since a minimum in peak target current and plasma potential was found in HiPIMS processes containing $\sim 50 \%$ of nitrogen. Time-resolved data for $\mathrm{Ar}^{+}$ions, presented in Sec. III C, will consider this matter further. Ar-ions of higher energy form a shoulder at $\sim 6 \mathrm{eV}$ for the pure Ar discharge. This shoulder moves towards lower energies as the $\mathrm{N}_{2}$ content increases in the sputter gas, but seem to stagnate at $\sim 2.4 \mathrm{eV}$ for processes containing $>50 \%$ of nitrogen. As expected, the quantity of these $\mathrm{Ar}^{+}$ions decreases rather linearly with 
increasing nitrogen content up to $50 \%$. A similar feature, although at slightly higher energies $(\sim 7.6 \mathrm{eV}$ for a process carried out in pure nitrogen ambient), can also be observed in IEDFs of $\mathrm{N}^{+}$.

Figures 3(e) and 3(f) present IEDFs for $\mathrm{N}_{2}{ }^{+}$and $\mathrm{N}^{+}$as a function of the nitrogen content in the sputter gas. As can be seen, nitrogen ions dominate the discharge as soon as reactive gas is introduced into the sputter chamber. Particularly, the IEDFs for $\mathrm{N}^{+}$show, next to a minor low energy peak originating from fully thermalized ions, a well-developed shoulder of high-energy species. As discussed above, the amount and energy of this portion of $\mathrm{N}^{+}$ions may only be compared to that of $\mathrm{C}^{+}$. With increasing nitrogen content in the sputter gas, the amount of the low-energy $\mathrm{N}^{+}$species decreases, while the amount of higher energetic ions is increasing. Moreover, the low-energy peak of $\mathrm{N}^{+}$ions shifts to higher energy values for increasing nitrogen contents up to $66 \%$ in the processes, simultaneously the low energy $\mathrm{N}_{2}{ }^{+}$ peak is moving towards lower energies.

Figures 4(a)-4(d) give a comparison of IEDFs recorded for a HiPIMS and a DCMS process. In the case of HiPIMS, the product of $E_{P}$ and frequency (corresponding to the average power) was comparable to the DCMS power. In both modes, the graphite target was sputtered in an atmosphere containing $50 \%$ nitrogen. The quantitative comparison of the shapes reveals for all the species lower energies in the DCMS process. Especially for $\mathrm{C}^{+}$ions, an increased amount and mean ion energy is found for the HiPIMS process. Moreover, only IEDFs recorded for $\mathrm{N}^{+}$in DCMS mode show a faint shoulder, which increases in amplitude and energy with increasing $\mathrm{N}_{2}$ content in the sputter gas and is found at $\sim 2.6 \mathrm{eV}$ for the process in pure $\mathrm{N}_{2}$ (not shown here). This dependency on the $\mathrm{N}_{2}$ content in the sputter gas is of the same order as it was found for the HiPIMS process (cf. Figure 3(e)). It should also be mentioned that IEDFs obtained for $\mathrm{C}^{+}, \mathrm{Ar}^{+}$, $\mathrm{N}_{2}{ }^{+}$, and $\mathrm{CN}^{+}$in DCMS mode barely present a correlation to the $\mathrm{N}_{2}$ content in the sputter gas (not shown here).
In Figure 5, the relative percentage of the detected ion fluxes $\left(\mathrm{C}^{+}, \mathrm{N}^{+}, \mathrm{Ar}^{+}, \mathrm{N}_{2}{ }^{+}, \mathrm{CN}^{+}\right.$, and $\left.\mathrm{C}_{2} \mathrm{~N}^{+}\right)$is presented as a function of the nitrogen content in the process gas for both sputter modes. In HiPIMS mode, the plasma chemistry is dominated by $\mathrm{N}^{+}$and $\mathrm{C}^{+}$ions as soon as $\mathrm{N}_{2}$ is introduced into the chamber. Thus, it can be assumed that $\mathrm{N}^{+}$and $\mathrm{C}^{+}$ ions also play a major role at the target, which explains the shape of the peak target current in dependence of $\mathrm{N}_{2}$ in the sputter gas (cf. inset Figure 2), because the overall amount of $\mathrm{C}^{+}$has a minimum between $14 \%$ and $66 \%$ of nitrogen in the sputter gas. Additionally, it accounts for the shape of the recorded IEDFs, as $\mathrm{C}^{+}$ions and considerable amounts of the high energetic portion of $\mathrm{N}^{+}$ions originate from the target. For the reactive HiPIMS process containing $>14 \%$ of nitrogen, the $\mathrm{Ar}^{+}$and the $\mathrm{N}_{2}^{+}$flux follow the same trend and decrease steadily with increasing nitrogen content, whereas the flux of $\mathrm{CN}^{+}$increases gradually with the nitrogen content, but remains low compared to the flux of $\mathrm{C}^{+}$and $\mathrm{N}^{+}$. As graphite is sputtered in DCMS mode with $14 \% \mathrm{~N}_{2}$ in the sputter gas, $\mathrm{N}_{2}{ }^{+}$is found to be the most abundant plasma specie. Next to $\mathrm{N}_{2}{ }^{+}, \mathrm{Ar}^{+}$, and $\mathrm{N}^{+}$ions are found to a considerable amount in the plasma containing $14 \%$ to $34 \%$ of $\mathrm{N}_{2}$. With the further increase of $\mathrm{N}_{2}$, the signals of $\mathrm{N}_{2}{ }^{+}$and $\mathrm{Ar}^{+}$decrease; at the same time, the $\mathrm{N}^{+}$ion flux rises and fully dominates the plasma composition. $\mathrm{C}_{2} \mathrm{~N}^{+}$ions are hardly observable with the applied measurement set up. It should be pointed out that the flux of $\mathrm{C}^{+}$ions does not play a major role as graphite is reactively DC-sputtered. This is in contrast to the HiPIMS mode once nitrogen is added to the process, $\mathrm{N}^{+}$followed by $\mathrm{C}^{+}$are found to be the most abundant plasma species.

\section{The carbon discharge as a function of the $\mathbf{N}_{2}$ content in the sputter gas: Time-resolved mass spectrometry}

Figures 6(a)-6(f) present time-resolved data for the most abundant species found in the HiPIMS plasma where a

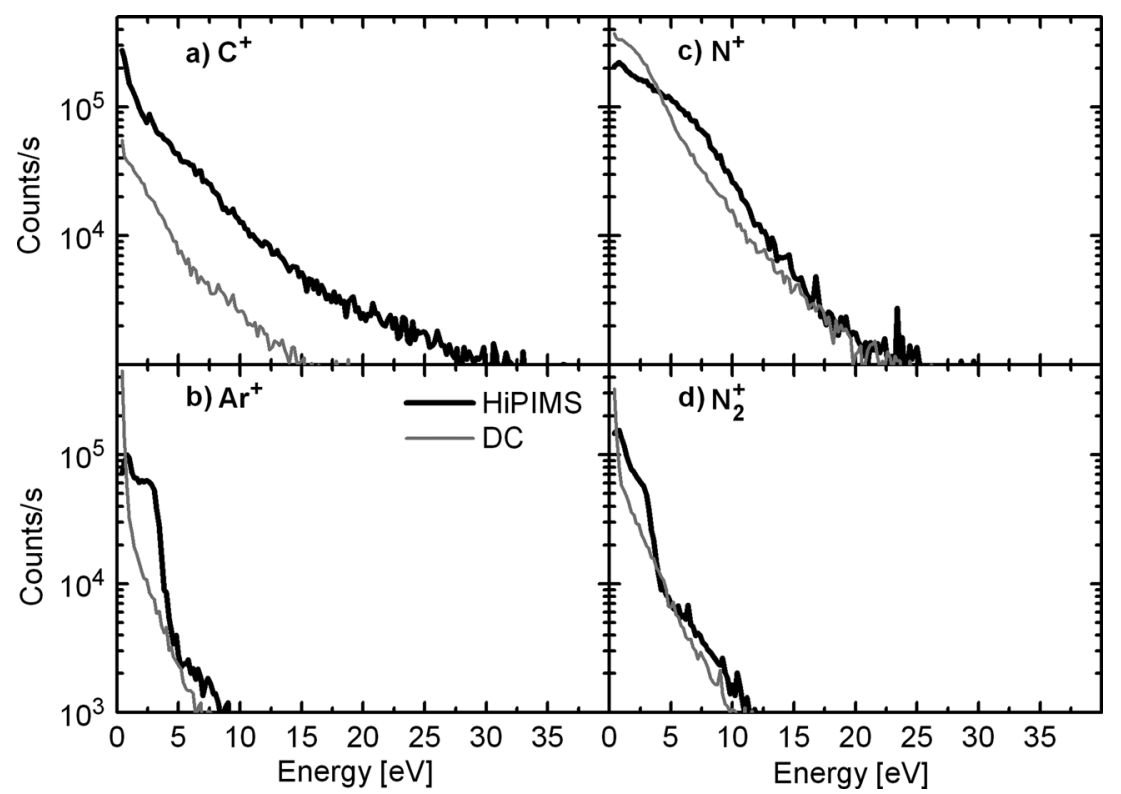

FIG. 4. (a)-(d) Comparison of HiPIMS and DCMS IEDFs for (a) $\mathrm{C}^{+}$, (b) $\mathrm{Ar}^{+}$, (c) $\mathrm{N}^{+}$, and (d) $\mathrm{N}_{2}^{+}$from time-averaged mass spectrometry measurements of a $\mathrm{C}$ discharge with $50 \% \mathrm{~N}_{2}$ in the sputter gas. 


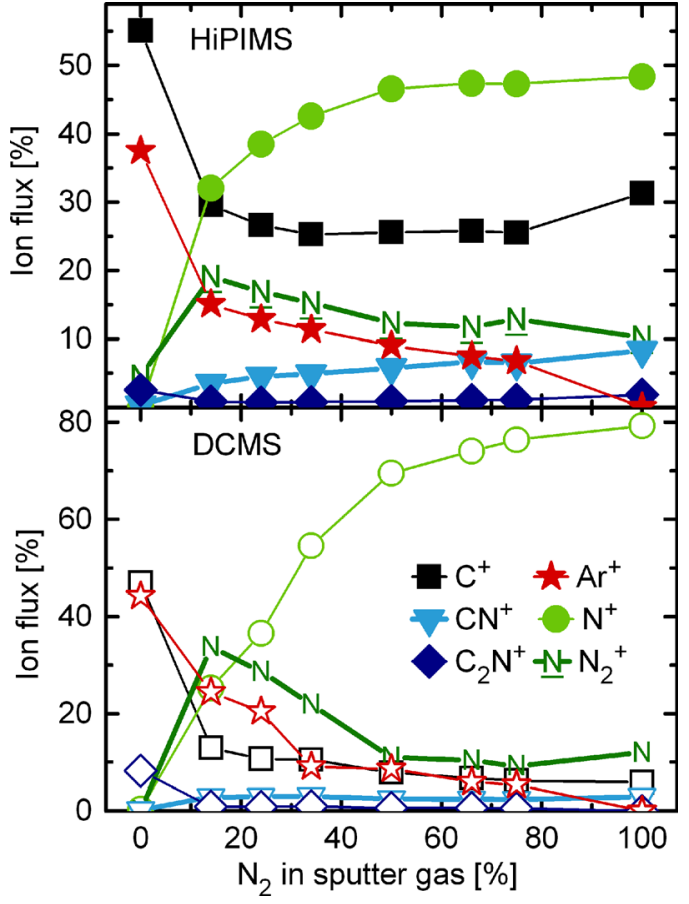

FIG. 5. The relative percentage of the detected ion fluxes in dependence of the nitrogen content in the process gas for both sputter modes. Solid symbols represent the ion flux extracted for HiPIMS and open symbols correspond to the ion fluxes obtained for DCMS.

graphite target was sputtered at different $\mathrm{Ar} / \mathrm{N}_{2}$-flow ratios. Here, data obtained during time-resolved mass-spectrometry measurements were integrated over the entire energy range of $30 \mathrm{eV}$. Hence, the count rate is presented as a function of the delay time, with respect to the pulse onset.

Up to a nitrogen content of $34 \%$ in the sputter gas, $\mathrm{Ar}^{+}$ and $\mathrm{N}_{2}{ }^{+}$ions are the first to arrive at the spectrometers orifice (Figures 6(a) and 6(b)). Fluxes of both ion species peak between $20 \mu \mathrm{s}$ and $40 \mu \mathrm{s}$ in the course of the pulse. As the nitrogen content in the sputter gas exceeds $34 \%$, the signals for $\mathrm{Ar}^{+}$and $\mathrm{N}_{2}^{+}$ions decrease in count rate and shift towards $60 \mu$ s and $70 \mu \mathrm{s}$, respectively. Interesting is the temporal comparison of the peak target current to the shift in delay time for the peak ion flux, since both progress in a similar manner (cf. Sec. III A) as $\mathrm{N}_{2}$ is introduced to the sputter process. This is ascribed to the decrease in Ar in the sputter gas accompanied with the simultaneous change of the target chemistry. Another noticeable feature is the distinct temporal evolution of the $\mathrm{N}_{2}{ }^{+}$ion flux curve, as a third peak evolves at $\sim 10 \mu$ s between $34 \%$ and $50 \%$ of $\mathrm{N}_{2}$ in the sputter gas and remains as a discrete peak for higher $\mathrm{N}_{2}$ contents. For $\mathrm{Ar}^{+}$ and $\mathrm{N}_{2}{ }^{+}$, a decay of the ion flux is observed through the second part of the pulse, but the signals pick up again at the end of the pulse and reach a new maximum at $\sim 200 \mu$ s after the pulse onset. Time-resolved data confirm that this late peak arises for all gas mixtures from low-energy (fully thermalized) ions. $\mathrm{Ar}^{+}$ions show a peculiar dependency in this post pulse region, as the maximum ion flux is found for a sputter process containing $14 \% \mathrm{~N}_{2}$ in the gas, followed by processes with $34 \%$ and $50 \%$ of $\mathrm{N}_{2}$. The above described dependency helps to understand time-averaged measurements, where the ions with lower energy and the thermalized ions gave a con-

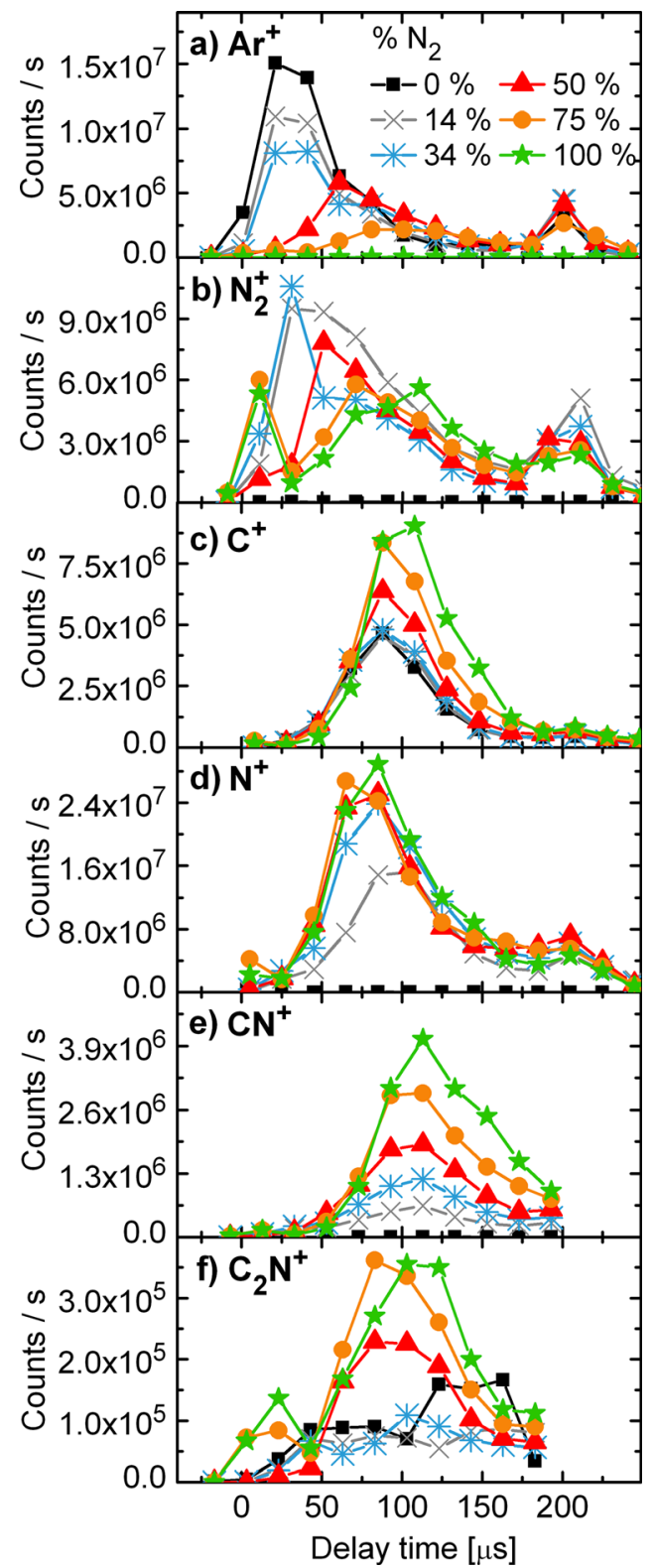

FIG. 6. (a)-(f). Total ion count rate $v s$ delay time (corresponding to the onset of the pulse) for different nitrogen contents in the sputter gas. Each data point represents IEDFs recorded during $20 \mathrm{~ms}$, integrated over the entire energy range for (a) $\mathrm{Ar}^{+}$, (b) $\mathrm{N}_{2}{ }^{+}$, (c) $\mathrm{C}^{+}$, (d) $\mathrm{N}^{+}$, (e) $\mathrm{CN}^{+}$, and (f) $\mathrm{C}_{2} \mathrm{~N}^{+}$.

trary impression as for the plasma potential and the low energy ion count. These ions arrive at the mass spectrometers orifice just after the pulse ended.

Signals obtained from $\mathrm{C}^{+}$and $\mathrm{N}^{+}$ions peak between $70 \mu \mathrm{s}$ and $110 \mu \mathrm{s}$ after the pulse onset (Figures 6(c) and 6(d)). A delay time of $\sim 100 \mu$ s corresponds to the beginning of the transition from HiPIMS to DCMS mode according to the discussed target current and target voltage waveforms (cf. Figure 2). For both species, no shift in delay time of the maximum ion flux is obtained for increased $\mathrm{N}_{2}$ fractions as described for $\mathrm{Ar}^{+}$and $\mathrm{N}_{2}{ }^{+}$ions. Nevertheless, as the $\mathrm{N}_{2} / \mathrm{Ar}$ ratio in the working gas rises above $50 \%$, the $\mathrm{C}^{+}$ion flux increases steadily, whereas the $\mathrm{N}^{+}$ion flux rises instantly as $\mathrm{N}_{2}$ is added to the process (see Sec. III B, Figure 5). The $\mathrm{C}^{+}$ and $\mathrm{N}^{+}$ions exhibit similar IEDFs in time-averaged measurement mode. Additionally, both IEDFs show a 
comparable temporal evolution in time-resolved measurements. This supports the theory that not only $\mathrm{C}^{+}$is originating from the target but also a large portion of $\mathrm{N}^{+}$ions.

$\mathrm{CN}^{+}$and $\mathrm{C}_{2} \mathrm{~N}^{+}$ions show a maximum count rate at $\sim 110 \mu$ s. While the $\mathrm{CN}^{+}$ion flux is heavily scaling with the $\mathrm{N}_{2}$ content in the working gas, the $\mathrm{C}_{2} \mathrm{~N}^{+}$ion flux rises first above the detection limit as $\mathrm{N}_{2}$ exceeds $50 \%$ in the sputter gas. However, the overall count rates for $\mathrm{C}_{2} \mathrm{~N}^{+}$and $\mathrm{CN}^{+}$ ions are rather low, owing to the comparatively bulky molecule dimensions and thus a higher collision probability in combination with the large distance between the target surface and the spectrometer's orifice. Moreover, a shift in delay time of the maximum ion flux is not observed for these plasma species as $\mathrm{N}_{2}$ is added to the process. This points towards the target as the origin of $\mathrm{CN}^{+}$and $\mathrm{C}_{2} \mathrm{~N}^{+}$, which is supported by the theory of the chemical sputter process occurring at the target surface. ${ }^{17,19,23,24}$

\section{DCMS vs. HiPIMS processes; their impact on $\mathrm{CN}_{\mathbf{x}}$ film growth and microstructure}

Compared to the DCMS discharge, HiPIMS exhibits most of all an increased amount of higher energy $\mathrm{C}^{+}$ions. $\mathrm{Ar}^{+}$and $\mathrm{N}^{+}$, though comparable in abundance, were also found to be more energetic, which in turn is accompanied by a significantly decreased amount of thermalized ions in the HiPIMS process (cf. Figure 4). The higher ion energy, the significant differences in plasma composition (cf. Figure 5) and a likely variation of the ion-to-neutral ratio imply influences on the growth and microstructure in $\mathrm{CN}_{\mathrm{x}}$ thin films sputtered by HiPIMS. In Figure 7 , the growth rates $\left(\mathrm{R}_{\mathrm{d}}\right)$ of comparable HiPIMS and DCMS processes are presented for different $\mathrm{N}_{2}$ contents in the sputter gas. Additionally, Figure 7 comprises the $\mathrm{R}_{\mathrm{d}}$ for different deposition temperatures (where RT-open symbols correspond to a deposition at room temperature, LT — crossed symbols to $\mathrm{T}_{\mathrm{s}}=110^{\circ} \mathrm{C}$, and HT-filled symbols to $\mathrm{T}_{\mathrm{s}}=430^{\circ} \mathrm{C}$ ). Striking is the high $\mathrm{R}_{\mathrm{d}}$ for non-reactive HiPIMS of graphite at high deposition temperatures. As soon as $\mathrm{N}_{2}(14 \%)$ is added to the sputter process, the deposition rates of all processes become similar. Increasing the $\mathrm{N}_{2}$ content further results in comparable $\mathrm{R}_{\mathrm{d}} \mathrm{s}$ for both sputter modes, but growth rates for processes at room, low, and high temperatures show a significant difference. At high temperatures and

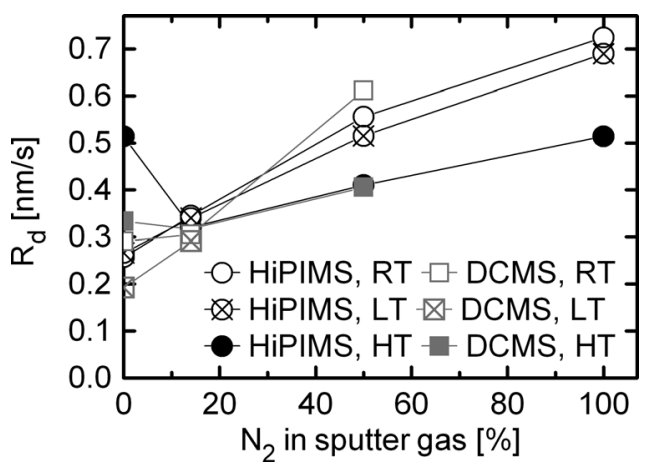

FIG. 7. Deposition rate $\left(\mathrm{R}_{\mathrm{d}}\right)$ vs $\mathrm{N}_{2}$ content in the sputter gas for HiPIMS and DCMS; where RT-open symbols correspond to depositions at room temperature, LT-crossed symbols to $110^{\circ} \mathrm{C}$ substrate temperature, and $\mathrm{HT}$ - filled symbols to $430^{\circ} \mathrm{C}$ substrate temperature. sputtering in pure $\mathrm{N}_{2}$, the growth rate reaches only $71 \%$ of the growth rate for a comparable process at low temperatures. Hellgren et $a l .{ }^{51}$ and Neidhardt et al. ${ }^{52}$ ascribed the lower deposition rates at elevated temperatures in reactive DCMS to chemical sputtering. Schluter et al. ${ }^{50}$ considered this dependency to be an indicator for chemical sputtering. The fact that no significant difference is seen for both modes implies the occurrence of similar sputter and growth mechanisms. This is in agreement with conclusions drawn from target current and target voltage waveforms in combination with time-average and time-resolved ion mass spectrometry.

Naturally, the deposition rate is connected to the density of thin films. Neidhardt et al. ${ }^{52}$ showed considerable variations in mass density as function of the $\mathrm{N}_{2}$ content in the sputter gas for thin films deposited at temperatures higher than $300^{\circ} \mathrm{C}$. This in turn correlated with very the interesting micro-structural evolution of $\mathrm{CN}_{\mathrm{x}} \quad(0<\mathrm{x}<0.23$, $\mathrm{T}_{\mathrm{S}}>300^{\circ} \mathrm{C}$ ) films; ranging from a-C to fullerene like to graphitic with increasing $\mathrm{N}_{2}$ content in the sputter gas. Figure 8 shows the corrected deposition rate (areal density deposited per second) in dependence of the $\mathrm{N}_{2}$ content in the sputter gas. Here, the deposition rates at a substrate temperature of $430^{\circ} \mathrm{C}$ (cf. HT, filled symbols, Figure 7) for HiPIMS and DCMS were multiplied with the film density, which was obtained from the film thickness (cross-sectional SEM) and the atomic areal density (ToF-ERDA). Since both the film density and the deposition rate were found to change considerably with the nitrogen content in the sputter gas, the presentation of the corrected $R_{d}$ is intended to pose a descriptive tool in order to compare different processes with regards to the amount of material deposited within a certain time. Obvious is the reduced corrected $\mathrm{R}_{\mathrm{d}}$ for sputtering in pure $\mathrm{Ar}$ atmosphere compared to values obtained for reactive processes in both sputter modes. This implies a low density for pure carbon films, which is more prominent for a-C films sputtered in HiPIMS mode. As soon as $\mathrm{N}_{2}$ is added to the process gas, the corrected $\mathrm{R}_{\mathrm{d}}$ increases rapidly. At $14 \% \mathrm{~N}_{2}$, the films produced in both sputter modes were found to posses comparable peak densities of $\sim 2 \mathrm{~g} \mathrm{~cm}^{-3}$. A further increase of $\mathrm{N}_{2}$ to $50 \%$ results merely in films with slightly increased corrected $\mathrm{R}_{\mathrm{d}} \mathrm{s}$, due to decreased film densities of $1.8 \mathrm{~g} \mathrm{~cm}^{-3}$ for both sputter modes. Films deposited by HiPIMS in pure $\mathrm{N}_{2}$ exhibit decreased densities of $1.4 \mathrm{~g} \mathrm{~cm}^{-3}$.

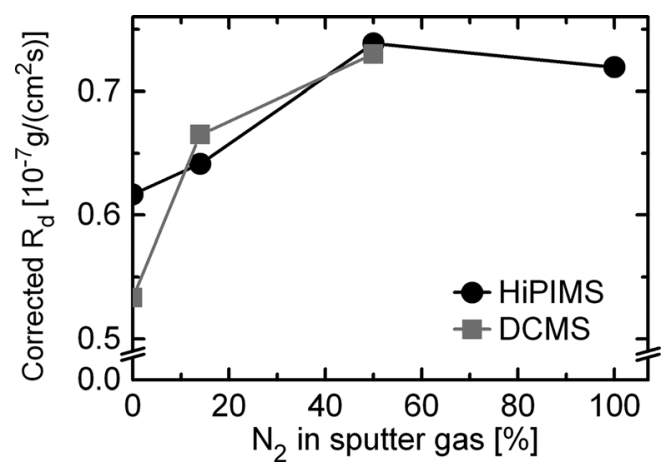

FIG. 8. Corrected deposition rate $\left(\mathrm{R}_{\mathrm{d}}\right)$ vs $\mathbf{N}_{2}$ content in the sputter gas for films deposited by HiPIMS and DCMS, at a substrate temperature of $430{ }^{\circ} \mathrm{C}$ and different $\mathrm{N}_{2}$ contents in the sputter gas. 
This evolution of the density is in agreement with results presented by Neidhardt et $_{\text {al }} .^{52}$

Figures 9(a)-9(d) show TEM images and SAED patterns from $\mathrm{C}$ and $\mathrm{CN}_{\mathrm{x}}$ thin films deposited by HiPIMS, where two different substrate temperatures and pulse energies as well as a process pressure of $400 \mathrm{mPa}$ were applied. Figures 9(a) and 9(b) present the microstructure of an a-C and a $\mathrm{CN}_{\mathrm{x}}$ thin film, produced with pure $\mathrm{Ar}$ and $\left[\mathrm{N}_{2}\right]=14 \%$, respectively, at $\mathrm{T}_{\mathrm{s}}=110^{\circ} \mathrm{C}$. Both films are effectively amorphous, but the $\mathrm{CN}_{\mathrm{x}}$ exhibits a slightly textured microstructure, with standing basal planes, judged by a ring segment of the $\sim 3.5 \AA$ ring in the SAED pattern directed in the substrate plane. The SAED patterns from $\mathrm{CN}_{\mathrm{x}}$ thin films exhibit usually three rings at $\sim 1.2 \AA, \sim 2 \AA$, and $\sim 3.5 \AA^{53}$ Diffuse SAED rings with a FWHM of $0.1 \AA^{-1}-0.2 \AA^{-1}$ and ring diameters of $\sim 1.2 \AA$ and $\sim 2 \AA$ are typical for amorphous carbon allotropes, whereas the appearance of the ring with a diameter of $\sim 3.5 \AA$ corresponds to graphitic short range order in the microstructures, i.e., in graphitic or FL-carbon materials. ${ }^{40}$ The evaluation of the SAED pattern in Figure 9(b) revealed an intensity ratio $\operatorname{int}(3.5 \AA) / \operatorname{int}(2 \AA)$ of 0.5 , which is the lowest value for $\mathrm{CN}_{\mathrm{x}}$ thin films studied here. The weak structuring of the $\mathrm{CN}_{\mathrm{x}}$ thin film shown in Figure 9(b) can be ascribed to the low deposition temperature. In fact, deposition temperatures of $>300{ }^{\circ} \mathrm{C}$ were defined by Neidhardt et al. to be one of the key requirements for the evolution of the fullerene-like short range order in $\mathrm{CN}_{\mathrm{x}}$ films. ${ }^{23}$ Thus, considering a similar film growth by chemical sputtering, it can be concluded that the low temperature is preventing a pronounced ordered microstructure. The lower panel, with Figures $9(\mathrm{c})$ and $9(\mathrm{~d})$, shows a comparison of $\mathrm{CN}_{\mathrm{x}}$ films deposited at $\mathrm{T}_{\mathrm{s}}=430^{\circ} \mathrm{C}$ with $\left[\mathrm{N}_{2}\right]=14 \%$, applying pulse ener-
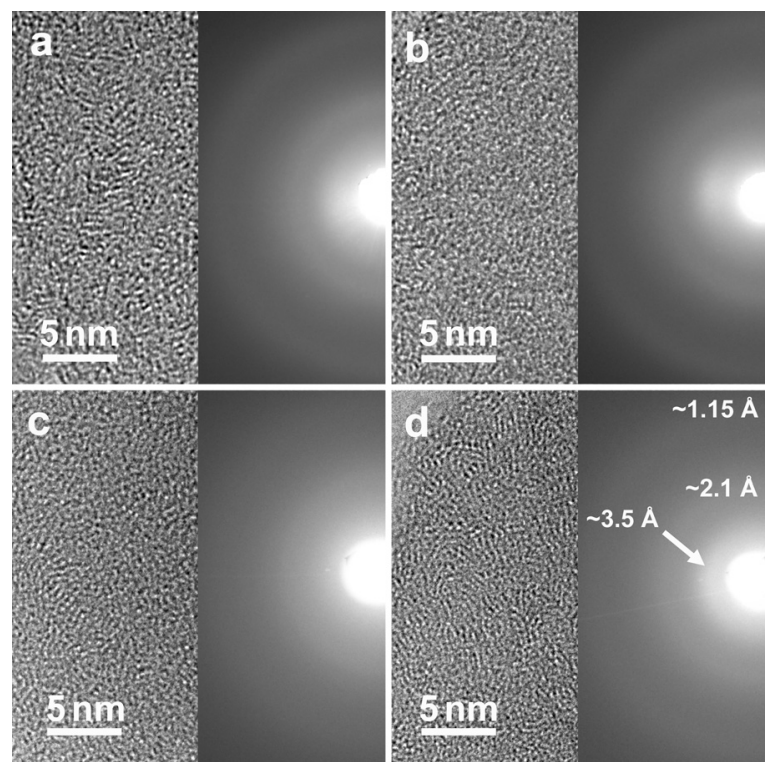

FIG. 9. (a)-(d) Cross-sectional HRTEM images with corresponding SAED patterns of $\mathrm{C}$ and $\mathrm{CN}_{\mathrm{x}}$ thin films deposited by HiPIMS: (a) a-C, $\mathrm{T}_{\mathrm{s}}=110^{\circ} \mathrm{C}$, (b) $\mathrm{CN}_{\mathrm{x}}, 14 \%$ nitrogen in the sputter gas, $\mathrm{T}_{\mathrm{s}}=110^{\circ} \mathrm{C}$, (c) $\mathrm{CN}_{\mathrm{x}}, 14 \%$ nitrogen in the sputter gas, $\mathrm{T}_{\mathrm{s}}=430^{\circ} \mathrm{C}$, and a pulse energy $\left(\mathrm{E}_{\mathrm{p}}\right)$ of $2.1 \mathrm{~J}$, as well as (d) $\mathrm{CN}_{\mathrm{x}}, 14 \%$ nitrogen in the sputter gas, $\mathrm{T}_{\mathrm{s}}=430^{\circ} \mathrm{C}, \mathrm{E}_{\mathrm{p}}=4.5 \mathrm{~J}$. The labels in the SAED pattern in panel (d) mark the positions of $\sim 1.15 \AA$ and $\sim 2.1 \AA$ diffuse rings. The arrow indicates the brightest segment of the $\sim 3.5 \AA$ ring. The growth direction in the HR images and SAED shows upwards. gies of $2.1 \mathrm{~J}$ and $4.5 \mathrm{~J}$, respectively. HRTEM images obtained from both films (2.1 J (Figure 9(c)) and 4.5 J (Figure 9(d)) indicate FL structure. Our former studies revealed no significant influences of the pulse energy on the microstructure of $\mathrm{CN}_{\mathrm{x}}$ thin films. However, the most distinct FL microstructure was obtained for the $\mathrm{CN}_{\mathrm{x}}$ film deposited with a pulse energy of $4.5 \mathrm{~J}$ (Figure $9(\mathrm{~d})$ ), this can be seen in the image and is indicated by an intensity ratio int $(3.5 \AA) / \operatorname{int}(2 \AA)=2.0$ extracted from the SAED pattern. Neidhardt et al. and Hellgren et al. as well as the presented study showed that the most pronounced features of fullerene likeness is found for films deposited at temperatures $>300{ }^{\circ} \mathrm{C}$ and low $f_{N 2 / A r}$. This in combination with the presented peak film densities found for $14 \%$ of $\mathrm{N}_{2}$ in the sputter gas at $430^{\circ} \mathrm{C}$ substrate temperature during deposition allows to conclude that FL films possess a very efficient, dense packing considering the amorphous nature with graphitic short range ordering (cf. Figure 9(d)).

For very thin (thickness $<50 \mathrm{~nm}$ ) $\mathrm{CN}_{\mathrm{x}}$ films, plan-view SAED in combination with TEM studies (not shown here) revealed, a change in the position of the inner ring to $\sim 4 \AA$, compared to $\sim 3.5 \AA$ reported in previous studies on related DCMS produced $\mathrm{CN}_{\mathrm{x}}$ thin films. ${ }^{40,53}$ The same shift of the inner ring from $\sim 3.5 \AA$ to $\sim 4 \AA$ was found for $\mathrm{CP}_{\mathrm{x}}$ thin films and related to an increased amount of intercalated P. ${ }^{54}$ Thus, we conclude that the shift of the inner ring is due to an increased amount of intercalated N. This, in turn, can be attributed to the apparent higher ion energy seen for HiPIMS, which is likely to cut bonds during fragment growth by chemical sputtering at the substrate. The higher ion energies obtained for HiPIMS may result in a strongly interlinked fullerene-like structure, similar to that of FL-CP ${ }_{\mathrm{x}}{ }^{55}$

Figures 10(a)-10(d) present TEM images with corresponding SAED pattern of $\mathrm{C}$ and $\mathrm{CN}_{\mathrm{x}}$ films produced by

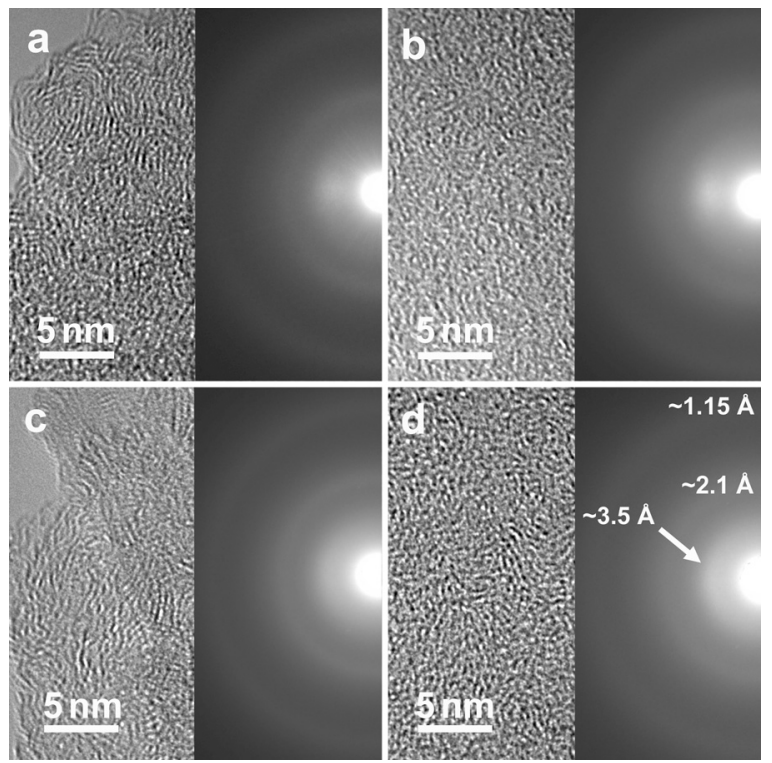

FIG. 10. (a)-(d) Cross-sectional HRTEM images with corresponding SAED pattern of $\mathrm{C}$ and $\mathrm{CN}_{\mathrm{x}}$ thin films deposited by DCMS with equivalent average power setting as films deposited by HiPIMS (cf. Figure 9 (a), (b), and (d)): (a) a-C, $\mathrm{T}_{\mathrm{s}}=110^{\circ} \mathrm{C}$, (b) $\mathrm{CN}_{\mathrm{x}}, 14 \%$ nitrogen in the sputter gas, $\mathrm{T}_{\mathrm{s}}=110^{\circ} \mathrm{C}$, (c) a-C, $\mathrm{T}_{\mathrm{s}}=430^{\circ} \mathrm{C}$, and (d) $\mathrm{CN}_{\mathrm{x}}, 14 \%$ nitrogen in the sputter gas, $\mathrm{T}_{\mathrm{s}}=430^{\circ} \mathrm{C}$. The labels in the SAED pattern in panel (d) mark the position of $\sim 1.15 \AA$ and $\sim 2.1 \AA$ diffuse rings. The arrow indicates the brightest segment of the $\sim 3.5 \AA$ ring. The growth direction in the HR images and SAED shows upwards. 
DCMS. Figures 10(a) and 10(c) show films sputtered from a graphite target in pure $\mathrm{Ar}$ at $110^{\circ} \mathrm{C}$ and $430^{\circ} \mathrm{C}$, respectively. The SAED patterns of both a-C films show a slight graphitic ordering with ring intensity ratios of 0.5. DCMS sputtered $\mathrm{CN}_{\mathrm{x}}$ films at temperatures of $110^{\circ} \mathrm{C}$ (Figure 10(b)) and $430^{\circ} \mathrm{C}$ (Figure $10(\mathrm{~d})$ ) were evaluated to ratios of 0.7 and 1.3 , respectively. The bright segment of the $\sim 3.5 \AA$ ring implies a slightly textured graphitic ordering of the $\mathrm{CN}_{\mathrm{x}}$ film (with preferred orientation of basal planes perpendicular to the substrate) seen in Figure 10(d). The comparison of TEM images and SAED patterns for HiPIMS $\mathrm{CN}_{\mathrm{x}}$ thin films and DCMS $\mathrm{CN}_{\mathrm{x}}$ thin films presented in this study reveals that the degree of ordering is highest for the HiPIMS $\mathrm{CN}_{\mathrm{x}}$ thin film sputtered in nitrogen containing atmosphere at $\mathrm{T}_{\mathrm{s}}=430^{\circ} \mathrm{C}$. Thus, it can be concluded that the structure-defining impact of chemical sputtering during $\mathrm{CN}_{\mathrm{x}}$ film growth is particularly effective in the HiPIMS process. This is evident from ion mass spectrometry, as more $\mathrm{C}_{\mathrm{x}} \mathrm{N}_{\mathrm{y}}(\mathrm{x}, \mathrm{y} \leq 2)$ ionic species, acting as structure-defining agents at the substrate, were found for the HiPIMS mode compared to DCMS (cf. Figure 5). However, high-energy particles may counteract the evolution of highly ordered microstructures in films deposited by HiPIMS.

\section{CONCLUSIONS}

Reactive DCMS and HiPIMS of graphite in an $\operatorname{Ar} / \mathrm{N}_{2}$ atmosphere yield a discharge that contains mainly $\mathrm{C}^{+}, \mathrm{N}^{+}$, $\mathrm{N}_{2}{ }^{+}$, as well as $\mathrm{Ar}^{+}$and to a lower extent $\mathrm{CN}^{+}$and $\mathrm{C}_{2} \mathrm{~N}^{+}$ions. The ion species in HiPIMS processes exhibit higher ion energies and a lower amount of fully thermalized ions compared to DCMS. With regards to ion energy and amount, $\mathrm{C}^{+}$ions exhibit distinct differences, with two and four orders of magnitude higher values, respectively, obtained for HiPIMS processing. Once nitrogen is added to the sputter process, $\mathrm{N}^{+}$-ions dominate the plasma chemistry. This effect is far less pronounced in the case of HiPIMS as the ion-flux at $50 \%$ of nitrogen in the process gas is composed of $26 \% \mathrm{C}^{+}$and $47 \%$ $\mathrm{N}^{+}$in contrast to the DCMS plasma, which contains $8 \%$ of $\mathrm{C}^{+}$ and $70 \%$ of $\mathrm{N}^{+}$at equivalent process settings. The comparison on the ion-flux shows further a rising amount of $\mathrm{C}_{\mathrm{x}} \mathrm{N}_{\mathrm{y}}(\mathrm{x}, \mathrm{y} \leq 2)$ species in the HiPIMS plasma. This in combination with the conclusions drawn from the evaluation of the target current confirms that chemical sputtering is active at the substrate and at target as soon as nitrogen is added to the sputter process.

The most pronounced FL structure is obtained for $\mathrm{CN}_{\mathrm{x}}$ films sputtered in HiPIMS mode at $430^{\circ} \mathrm{C}$. Pure carbon thin films as well as $\mathrm{CN}_{\mathrm{x}}$ thin films deposited at low substrate temperatures of $110^{\circ} \mathrm{C}$ exhibit only slight graphitic short range ordering. In the case of HiPIMS, the increased amount of pre-formed ionic $\mathrm{C}_{\mathrm{x}} \mathrm{N}_{\mathrm{y}}$ $(\mathrm{x}, \mathrm{y} \leq 2)$ species by chemical sputtering at high temperatures promotes the formation of FL- $\mathrm{CN}_{\mathrm{x}}$. The comparatively high energies detected for $\mathrm{N}^{+}$and $\mathrm{C}^{+}$ions in the HiPIMS process disturb the FL structure by intercalation of $\mathrm{N}$ in the films.

\section{ACKNOWLEDGMENTS}

The VINN Excellence Center Functional Nanoscale Materials (FunMat) is acknowleged. We are thankful for the access to the Tandem Laboratory, Uppsala University. Zsolt
Czigány acknowledges the Bolyai Scholarship of the Hungarian Academy of Sciences.

${ }^{1}$ J. Robertson, Adv. Phys. 35, 317-374 (1986).

${ }^{2}$ J. Robertson, Pure Appl. Chem. 66, 1789-1796 (1994).

${ }^{3}$ Y. Lifshitz, Diamond Relat. Mater. 5, 388-400 (1996).

${ }^{4}$ Y. Lifshitz, Diamond Relat. Mater. 8, 1659-1676 (1999).

${ }^{5}$ J. Robertson, Mater. Sci. Eng. R 37, 129-281 (2002).

${ }^{6}$ J. Robertson, Prog. Solid State Chem. 21, 199-333 (1991).

${ }^{7}$ J. Robertson, Surf. Coat. Technol. 50, 185-203 (1992).

${ }^{8}$ J. Robertson, Thin Solid Films 383, 81-88 (2001).

${ }^{9}$ A. A. Voevodin, C. Rebholz, J. M. Schneider, P. Stevenson, and A. Matthews, Surf. Coat. Technol. 73, 185-197 (1995).

${ }^{10}$ T. Mikami, H. Nakazawa, M. Kudo, and M. Mashita, Thin Solid Films 488, 87-92 (2005).

${ }^{11}$ C. A. Davis, G. A. J. Amaratunga, and K. M. Knowles, Phys. Rev. Lett. 80, 3280-3283 (1998).

${ }^{12}$ J. C. Angus and C. C. Hayman, Science 241, 913-921 (1988).

${ }^{13}$ J. Robertson, Phys. Rev. Lett. 68, 220-223 (1992).

${ }^{14}$ A. Grill, Diamond Relat. Mater. 12, 166-170 (2003).

${ }^{15}$ S. S. Tinchev, Y. Dyulgerska, P. Nikolova, D. Grambole, U. Kreissig, and T. Z. Babeva, J. Optoelectron. Adv. Mater. 8, 308-311 (2006).

${ }^{16}$ C. Casiraghi, J. Robertson, and A. C. Ferrari, Mater. Today 10, 44-53 (2007).

${ }^{17}$ N. Hellgren, K. Macak, E. Broitman, M. P. Johansson, L. Hultman, and J. E. Sundgren, J. Appl. Phys. 88, 524-532 (2000).

${ }^{18}$ B. Kleinsorge, A. C. Ferrari, J. Robertson, W. I. Milne, S. Waidmann, and S. Hearne, Diamond Relat. Mater. 9, 643-648 (2000).

${ }^{19}$ J. Neidhardt, L. Hultman, E. Broitman, T. W. Scharf, and I. L. Singer, Diamond Relat. Mater. 13, 1882-1888 (2004).

${ }^{20}$ G. Abrasonis, R. Gago, M. Vinnichenko, U. Kreissig, A. Kolitsch, and W. Moller, Phys. Rev. B 73, 13 (2006).

${ }^{21}$ R. Kaltofen, T. Sebald, and G. Weise, in Plasma Diagnostic Studies to the Carbon Nitride Film Deposition by Reactive Rf Magnetron Sputtering (Elsevier Science Sa Lausanne, 1996), pp. 112-119.

${ }^{22}$ S. E. Rodil and S. Muhl, Diamond Relat. Mater. 13, 1521-1531 (2004).

${ }^{23}$ J. Neidhardt, Z. Czigany, I. F. Brunell, and L. Hultman, J. Appl. Phys. 93, 3002-3015 (2003).

${ }^{24}$ L. Hultman, J. Neidhardt, N. Hellgren, H. Sjostrom, and J. E. Sundgren, MRS Bull. 28, 194-202 (2003).

${ }^{25}$ V. Kouznetsov, K. Macak, J. M. Schneider, U. Helmersson, and I. Petrov, Surf. Coat. Technol. 122, 290-293 (1999).

${ }^{26}$ J. Bohlmark, M. Ostbye, M. Lattemann, H. Ljungcrantz, T. Rosell, and U. Helmersson, Thin Solid Films 515, 1928-1931 (2006).

${ }^{27}$ A. P. Ehiasarian, R. New, W. D. Munz, L. Hultman, U. Helmersson, and V. Kouznetsov, in Influence of High Power Densities on the Composition of Pulsed Magnetron Plasmas (Pergamon, 2002), pp. 147-154.

${ }^{28}$ J. T. Gudmundsson, J. Alami, and U. Helmersson, Surf. Coat. Technol. 161, 249-256 (2002).

${ }^{29}$ A. P. Ehiasarian, W. D. Munz, L. Hultman, U. Helmersson, and I. Petrov, Surf. Coat. Technol. 163, 267-272 (2003).

${ }^{30}$ G. Hakansson, L. Hultman, J. E. Sundgren, J. E. Greene, and W. D. Munz, Surf. Coat. Technol. 48, 51-67 (1991).

${ }^{31}$ I. Petrov, F. Adibi, J. E. Greene, L. Hultman, and J. E. Sundgren, Appl. Phys. Lett. 63, 36-38 (1993).

${ }^{32}$ B. M. DeKoven, P. R. Ward, R. E. Weiss, D. J. Christie, R. A. Scholl, W. D. Sproul, F. Tomasel, and A. Anders, in Carbon Thin Film Deposition Using High Power Pulsed Magnetron Sputtering (2003), pp. 158-165.

${ }^{33}$ A. Hecimovic, K. Burcalova, and A. P. Ehiasarian, J. Phys. D: Appl. Phys. 41, 10 (2008).

${ }^{34}$ A. Hecimovic and A. P. Ehiasarian, IEEE Trans. Plasma Sci. 39, 1154-1164 (2011).

${ }^{35}$ J. Bohlmark, M. Lattemann, J. T. Gudmundsson, A. P. Ehiasarian, Y. A. Gonzalvo, N. Brenning, and U. Helmersson, Thin Solid Films 515, 1522-1526 (2006).

${ }^{36}$ H. J. Whitlow, G. Possnert, and C. S. Petersson, Nucl. Instrum. Methods Phys. Res. B 27, 448-457 (1987).

${ }^{37}$ J. Jensen, D. Martin, A. Surpi, and T. Kubart, Nucl. Instrum. Methods Phys. Res. B 268, 1893-1898 (2010).

${ }^{38}$ J. P. McCaffrey, Microsc. Res. Tech. 24, 180-184 (1993).

${ }^{39}$ J. L. Labar, Microsc. Microanal. 15, 20-29 (2009).

${ }^{40}$ Z. Czigany and L. Hultman, Ultramicroscopy 110, 815-819 (2010).

${ }^{41}$ G. Greczynski and L. Hultman, Vacuum 84, 1159-1170 (2010). 
${ }^{42}$ A. Anders, Surf. Coat. Technol. 205, S1-S9 (2011).

${ }^{43}$ S. M. Rossnagel, J. Vac. Sci. Technol. A 6, 19-24 (1988).

${ }^{44}$ N. Hellgren, M. P. Johansson, E. Broitman, L. Hultman, and J.-E. Sundgren, Phys. Rev. B 59, 5162 (1999)

${ }^{45}$ E. P. L. Hunter and S. G. Lias, J. Phys. Chem. Ref. Data 27, 413-656 (1998).

${ }^{46}$ V. H. Dibeler, R. M. Reese, and J. L. Franklin, J. Am. Chem. Soc. 83 , 1813-1818 (1961).

${ }^{47}$ R. C. Wetzel, F. A. Baiocchi, T. R. Hayes, and R. S. Freund, Phys. Rev. A 35, 559-577 (1987).

${ }^{48}$ J. Roth, "Chemical sputtering," in Sputtering by Particle Bombardment II, edited by R. Behrisch (Springer, Berlin Heidelberg, 1983), Chap. 3.5, pp. 116-146.
${ }^{49}$ W. Jacob, C. Hopf, and M. Schluter, Appl. Phys. Lett. 86, 204103 (2005).

${ }^{50}$ M. Schlueter, C. Hopf, and W. Jacob, New J. Phys. 10, 17 (2008).

${ }^{51}$ Hellgren, M. P. Johansson, E. Broitman, P. Sandstrom, L. Hultman, and J. E. Sundgren, Thin Solid Films 382, 146-152 (2001).

${ }^{52}$ J. Neidhardt, H. Hogberg, and L. Hultman, Thin Solid Films 478, 34-41 (2005).

${ }^{53}$ J. Neidhardt, L. Hultman, and Z. Czigany, Carbon 42, 2729-2734 (2004).

${ }^{54}$ G. K. Gueorguiev, Z. Czigany, A. Furlan, S. Stafstrom, and L. Hultman, Chem. Phys. Lett. 501, 400-403 (2011).

${ }^{55}$ G. K. Gueorguiev, A. Furlan, H. Hogberg, S. Stafstrom, and L. Hultman, Chem. Phys. Lett. 426, 374-379 (2006). 